\title{
Endoworm: A new semi-autonomous enteroscopy device
}

\author{
Proc IMechE Part H: \\ $J$ Engineering in Medicine \\ I-7 \\ (c) IMechE 2018 \\ Article reuse guidelines: \\ sagepub.com/journals-permissions \\ DOI: $10.1177 / 0954411918806330$ \\ journals.sagepub.com/home/pih \\ (SAGE
}

\author{
Carlos Sánchez-Diaz', Esther Senent-Cardona ${ }^{2}$, \\ Vicente Pons-Beltran ${ }^{3}$, Alberto Santonja-Gimeno ${ }^{4}$ and Ana Vidaurre ${ }^{2}$
}

\begin{abstract}
Using enteroscopes with therapeutic capacity to explore the small intestine entails certain limitations, including long exploration times, patient discomfort, the need for sedation, a high percentage of incomplete explorations and a long learning curve. This article describes the advances and setbacks encountered in designing the new Endoworm enteroscopy system, a semi-autonomous device consisting of a control unit and three cavities that inflate and deflate in such a way that the bowel retracts over the endoscope. The system can be adapted to any commercial enteroscope. Endoworm was tested in different intestine models: a polymethyl methacrylate rigid tube, an in vitro polyester urethane model, an ex vivo pig model and an in vivo animal model. The general behavior of the prototype was evaluated by experienced medical personnel. The mean distance covered through the lumen was measured in each cycle. The system was found to have excellent performance in the rigid tube and in the in vitro model. The ex vivo tests showed that the behavior depended largely on the mechanical properties of the lumen, while the in vivo experiments suggest that the device will require further modifications to improve its performance.
\end{abstract}

\section{Keywords \\ Endoscopy, gastroenterology, medical control systems, medical diagnosis}

Date received: I4 June 2018; accepted: I4 September 2018

\section{Introduction}

Clinicians currently have several means of exploring the small bowel at their disposal: double-balloon enteroscopy (DBE), ${ }^{1,2}$ single-balloon enteroscopy (SBE), ${ }^{3}$ spiral enteroscopy (SE) ${ }^{4}$ and capsule endoscopy..$^{5}$ All of them are devices which can carry out explorations in almost the whole of the small bowel. Capsule endoscopy, used for diagnosis only, is a powerful tool in assessing problems in the small bowel. ${ }^{6}$ The other systems can detect small bowel lesions almost as well as capsule endoscopy, with the advantage of being able to deliver therapeutic treatments. ${ }^{7}$ Although comparative studies of the different systems have not been able to establish one system as superior to the others, ${ }^{8,9} \mathrm{DBE}$ is considered the standard endoscopic technique for visualization and minimally invasive therapy in the small bowel. However, it also has some limitations: long exploration time, discomfort for the patient, sedation is required, incomplete explorations and high consumption of resources (especially human resources as the procedure needs at least two people). ${ }^{10} \mathrm{Chen}$ et al. ${ }^{11}$ reported frequent complaints of discomfort, including sore throat, nausea, abdominal distension and abdominal pain, during the examination. Post-procedural bleeding has been described as a complication of diagnostic DBE in up to $15 \%$ of procedures, ${ }^{12}$ and the re-bleeding rate after a negative DBE is considerable. ${ }^{13}$ Regarding the intubation depth, all the techniques achieve comparable exploration depth of the small bowel. Mean intubation depth varies with the system used: $239 \mathrm{~cm}$ for DBE, $233 \mathrm{~cm}$ for $\mathrm{SBE}$ and $236 \mathrm{~cm}$ for $\mathrm{SE}$ in the case of oral intubation, and $130 \mathrm{~cm}$ for DBE,

\footnotetext{
'Department of Electronic Engineering, Universitat Politècnica de València, València, Spain

${ }^{2}$ Center for Biomaterials and Tissue Engineering (CBIT), Universitat Politècnica de València and Biomedical Research Networking Center in Bioengineering, Biomaterials and Nanomedicine (CIBER-BBN), València, Spain

${ }^{3}$ Unidad de Endoscopia Digestiva, Servicio de Medicina Digestiva, Hospital Universitari i Politècnic La Fe, Digestive Endoscopy Reserch Group, IIS La FE, València, Spain

${ }^{4}$ Escuela Técnica Superior de Ingeniería del Diseño (ETSID), Universitat Politècnica de València, València, Spain
}

\section{Corresponding author:}

Carlos Sánchez-Diaz, Department of Electronic Engineering, Universitat Politècnica de València, Camino de Vera, s/n, 46022 València, Spain.

Email: csanched@eln.upv.es 
$123 \mathrm{~cm}$ for $\mathrm{SBE}$ and $88 \mathrm{~cm}$ for $\mathrm{SE}$ in the case of anal intubation. $^{14-16}$

The robotic endoscope is capable of self-propelling locomotion in the gastrointestinal tract. In 1995, Grundfest et al. ${ }^{17}$ published the preliminary results of a robotic endoscope based on pneumatic actuators with lighting and imaging capacities. Since then, new generation of robotic endoscope has improved enabling better clinical application. In Menciassi and Dario, ${ }^{18}$ a study of different bio-inspired methods for locomotion in the gastrointestinal tract is presented. All of them are based on the natural frictional interaction between the robot and the intestinal surface. Among the different propulsion mechanisms proposed, we found multiple-balloon system with no moving parts or electronics, ${ }^{19}$ rotational motion of a spiral-shaped body, or expansion and contraction motion of a stretchable body. ${ }^{20}$ In Zarrouk et al., ${ }^{21}$ a detailed numerical simulation of the interaction between earthworm robots and biological tissues is provided. Although some of the findings may help in the design of the motion control of new systems, the main drawback of robotic systems is that, apart from colonoscopy, ${ }^{22}$ they cannot be used to deliver therapies. ${ }^{23,24}$

The device described here is a semi-autonomous system that combines the robotics with the balloon enteroscopy systems. The system, although can be selfpropelled, would not be able to advance a conventional endoscope through the small bowel. For this reason, it is designed to be manipulated by a specialist, progressing along the small bowel while retracting the bowel over the endoscope. The device is named Endoworm and it was inspired by Bionics (caterpillar movement).

This article deals with the Endoworm prototype. The system was conceived as an easy-to-handle device to facilitate the work of medical staff during explorations. To our knowledge, there is no system at present available that combines the advantages of an autonomous system with the diagnostic and therapeutic capacities of the current enteroscopes.

\section{Endoworm prototype}

The Endoworm prototype is a semi-autonomous device which helps the specialist to operate the endoscope inside the small bowel. Its goal is to retract the intestine over the endoscope in order to help its advance. It consists of a pneumatic system governed by an electronic microcontroller. The pneumatic system is composed of two balloons and a bellows (pneumatic engine) that are inflated and deflated in cycles by means of a pressure pump that stores compressed air in a tank and a vacuum pump that keeps a certain volume of air at a vacuum pressure in another tank. The microcontroller software was designed to achieve the coordinated inflation and deflation of the cavities. The balloons grip the inner bowel wall and the bellows is for propulsion when the small bowel retracts. Figure 1 shows the block diagram of the hardware, including the digital controller and the pneumatic system. The microcontroller card is based on a PIC18F4550 8-bit Microchip

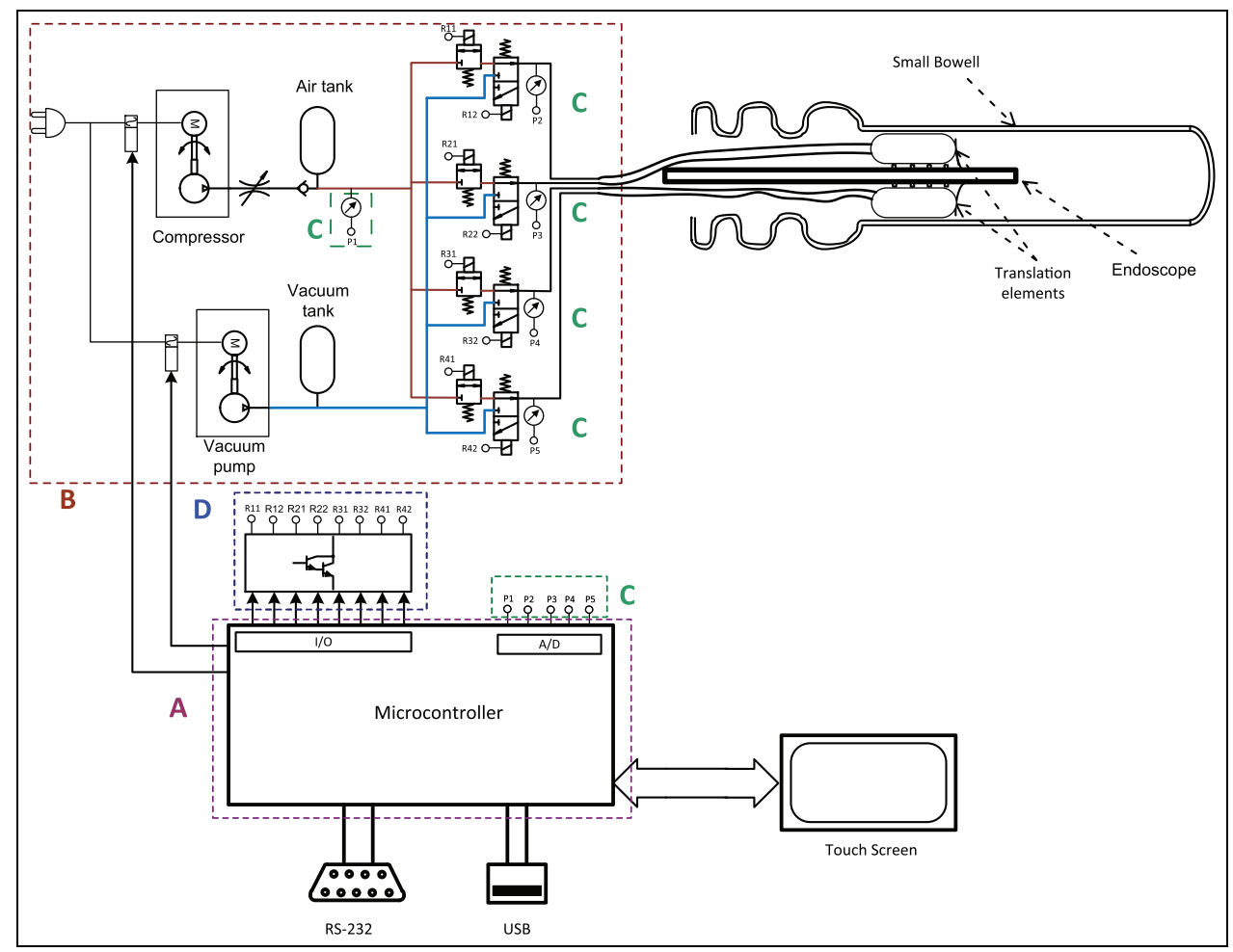

Figure I. Block diagram of the hardware control system.

A, central processor unit; B, pneumatic control system; C, pressure sensors; D, power drivers to control solenoid valves. 
Table I. Mechanical properties of the studied materials (information provided by the supplier).

\begin{tabular}{llllllll}
\hline & Q7-4735 & Q7-4720 & Sylgard I84 & MDX4-4210 & $7-6830$ & $7-4870$ & CL2250 \\
\hline Hardness (Shore A) & 35 & 22 & 50 & 30 & 30 & 66 & 50 \\
Tensile strength (MPa) & 9.84 & 9.29 & 7.1 & 5 & 8.8 & 9.5 & 5.70 \\
Tear resistance (kN/m) & 36.6 & 32.2 & 2.6 & - & 25 & 47 & 24.5 \\
Elongation(\%) & 1.171 & 1.283 & 140 & 470 & 790 & 420 & 760 \\
Modulus, 200\% (MPa) & 1.11 & 0.40 & - & - & 0.9 & 5.7 & - \\
\hline
\end{tabular}

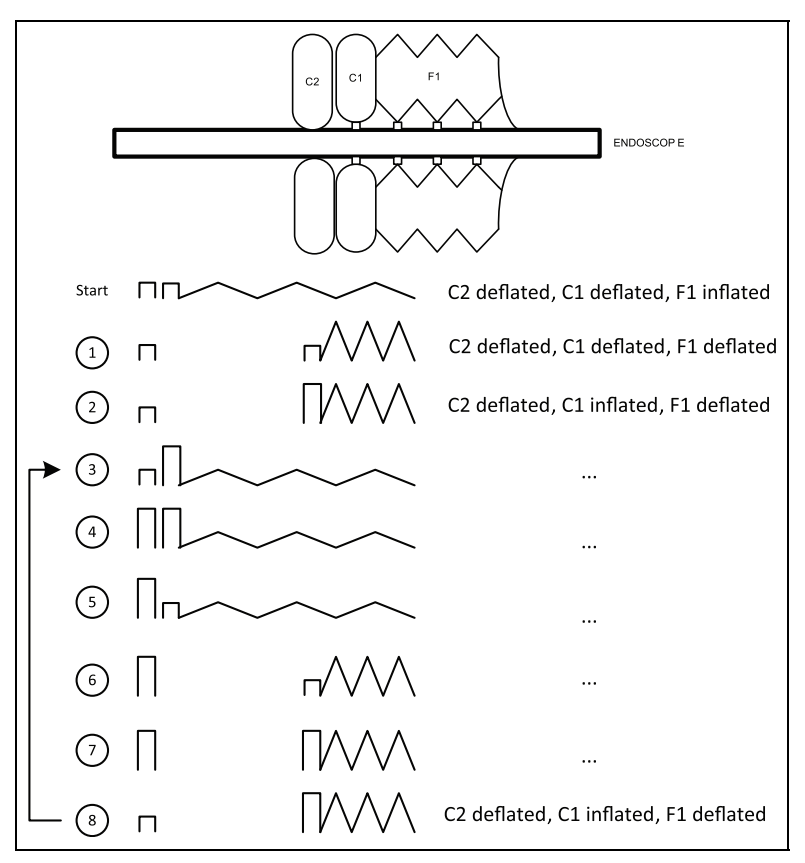

Figure 2. Diagram of the cavity movement sequence. $\mathrm{C} 2$, holding balloon; $\mathrm{CI}$, mobile balloon; $\mathrm{FI}$, bellows.

microcontroller, while the software coordinates movements by controlling air pressures in the head of the air connections.

Figure 2 shows the position of the three cavities and the sequence of movements. The mobile balloon $(\mathrm{C} 1)$ retracts the intestine in States 2 and 3. The fixed balloon (C2) holds the retracted intestine in State 4, and States 5 and 6 return the mobile balloon to its initial state to restart the cycle.

\section{Materials used in the inflatable cavities}

Biocompatible materials are compulsory for use in humans. Of these, silicone was selected for the inflatable cavities due to the wide range of these materials able to fulfill the mechanical requirements. A preliminary study was performed to select the material with the best behavior for each cavity type. Those considered were the following: Silastic Biomedical Grade ETR Elastomers Q7-4735 and Q7-4720, Sylgard 184 Silicone Elastomer, Silastic MDX4-4210 Biomedical Grade Elastomers, Silastic 7-6830 and 7-4870 Biomedical Grade Líquid Silicone Rubbers (Dow Corning ${ }^{\circledR}$ ) and
VersaflexTM CL2250 Thermoplastic Elastomer $\left(\right.$ PolyOne ${ }^{\mathrm{TM}}$ ). Table 1 shows their mechanical properties as provided by the suppliers.

Silastic Biomedical Grade ETR Elastomer Q7-4720 had the maximum elongation and the minimum elastic modulus, one of the most important requirements for $\mathrm{C} 1$ and $\mathrm{C} 2$ cavities. A big elongation allows to reach a high volume and therefore a higher fixation to the intestine, and a low elastic module allows to use lower compressed air pressures. After testing different configurations, Q7-4720 was found to have the best behavior for the $25-\mathrm{mm}$ diameter cavity (at rest) with a $0.4-\mathrm{mm}$ thick wall. This cavity was found to last under normal working conditions (consecutive inflation at air pressure of $150 \mathrm{kPa}$ and deflation at $710 \mathrm{mmHg}$ of vacuum) for more than $2 \mathrm{~h}$.

7-4870 silicone was found to give the best performance for the bellows, which had to expand in the forward direction but not sideways. Its axial displacement was similar to 7-6830, but its radial expansion was lower, due to its high elastic modulus. Although a priori Sylgard 184 silicone may have a better performance for the bellows, it was frequently broken in the removal from the mold, due to its low elongation coefficient (Table 1).

The cavities manufactured with 7-4870 silicone also lasted for more than $2 \mathrm{~h}$ under normal working conditions. The balloons and the external wall of the bellows were molded using the specified materials and following the manufacturer's instructions. The same mold was used for all the materials.

In the previous designs, ${ }^{25}$ the bellows expanded satisfactorily, but retraction was not effective enough for forward mobility. A new retraction system was thus added. In the third-generation prototype, the bellows had a tubular latex internal wall (but no second bellows, as in the previous prototypes), and three equally separated elastic straps were added to retract the mobile balloon when vacuum was applied. To reduce the radial expansion of the wall, thicker outer rings were used. Figure 3 shows the final pneumatic system attached to an endoscope model. When balloons deflated, they have practically the ring diameter, and when inflated, the balloons have a diameter of $45 \mathrm{~mm}$. At rest, the bellows is $40 \mathrm{~mm}$ long and has a $17-\mathrm{mm}$ diameter, is $26 \mathrm{~mm}$ long when deflated and is $50 \mathrm{~mm}$ long with a diameter of $21.5 \mathrm{~mm}$ when fully inflated. 


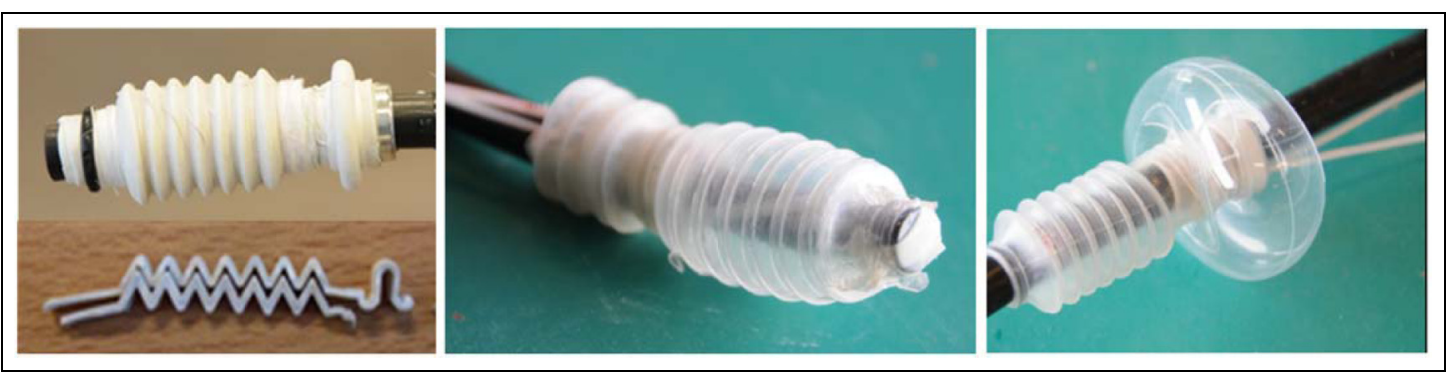

Figure 3. Pneumatic engine mounted on an endoscope model: (left) Previous prototype; (center), current prototype bellows inflated, mobile balloon deflated; (right), current prototype mobile balloon inflated, bellows deflated.

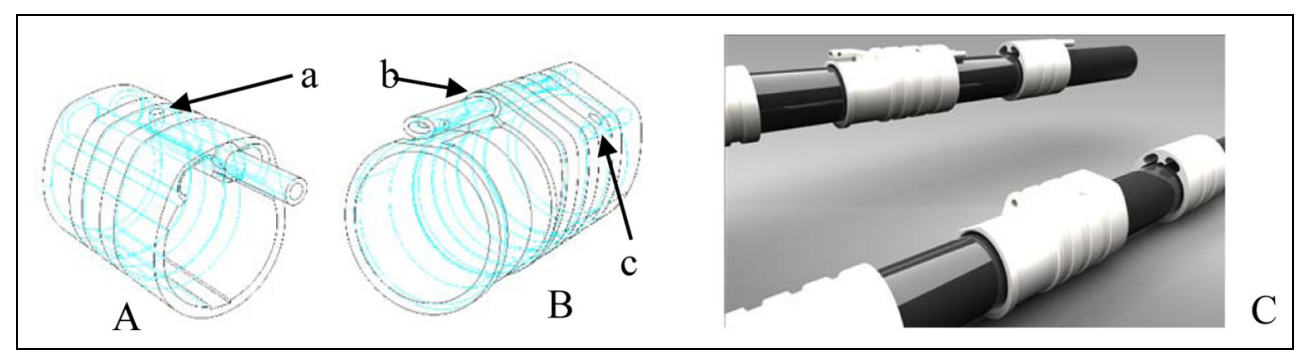

Figure 4. Cavity support rings: (A) fixed balloon including air supply tube (a); (B) mobile balloon and bellows including bellows air supply tube (b) and mobile air supply tube (c); (C) view of rings attached to endoscope.

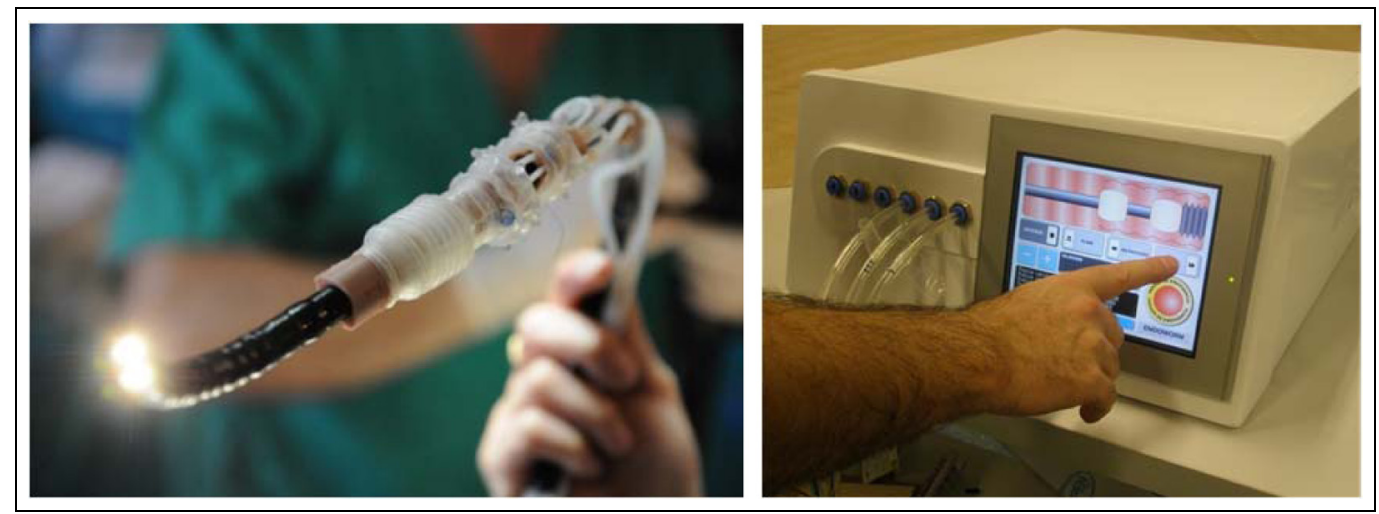

Figure 5. View of Endoworm attached to an (left) Olympus SIF-QI80 enteroscope and (right) the control unit.

\section{Support rings}

The previous prototypes had shown that the radial expansion cavities had to be mounted on special rings that fulfilled two requirements: they had to support the cavities and also provide air to them. As the extruded aluminum rings used in the previous prototypes could not be made with enough precision (internal air ducts made by die-cutting with very small diameters), oxetane resin rings were made by the stereolithography technique. This production method consists of adding layers of a minimum thickness of $50 \mu \mathrm{m}$. The oxetane resin has equivalent properties to polyethylene and has the advantage that the pieces can subsequently be machined if necessary. Figure 4 shows the rings designed for the fixed and mobile balloons and bellows support. The inner diameter of the rings is $10.8 \mathrm{~mm}$ and wall thickness is $1.4 \mathrm{~mm}$, so the outer diameter is $13.6 \mathrm{~mm}$. The air tubes pass under the fixed balloon ring. The mobile balloon ring supplies air to the mobile balloon and the bellows cavity. The maximum outer dimension of the rings is $14.7 \mathrm{~mm}$ to allow the pipes to pass through. The longest is $30.8 \mathrm{~mm}$ (Figure 4B).

\section{Experimental tests}

The Endoworm pneumatic system was attached to an Olympus SIF-Q180 enteroscope (Figure 5) with a diameter of $9.8 \mathrm{~mm}$ and tested in different intestine models: in vitro, in rigid and flexible tubes, ex vivo and in vivo. The system allows the insertion of the endoscope through the rings and fixation thanks to a removable tab system. In all the cases, the air pressure in the 


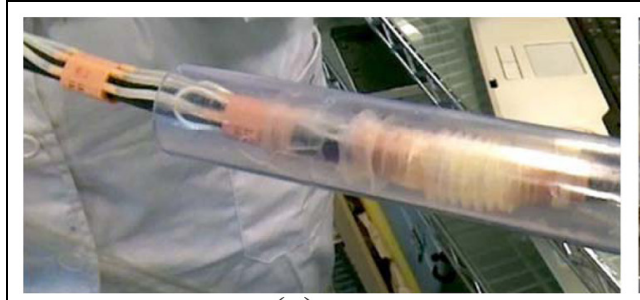

(a)

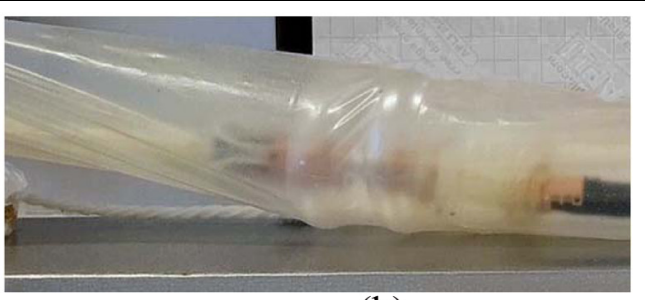

(b)

Figure 6. Endoworm system test in a (a) PMMA rigid tube and (b) in vitro PU model.

control system was set to $150 \mathrm{kPa}$ and vacuum to $710 \mathrm{mmHg}$. The maximum pressure was set considering the correct working of the cavities without compromising the patient's health. Vacuum was set to deflate the cavities as fast as possible.

The rigid tube was a transparent polymethyl methacrylate (PMMA) tube with an inner diameter of $40 \mathrm{~mm}$ (Figure 6(a)). This model allows to analyze the movement of the system, reducing the number of environmental variables. The diameter of the small bowel gradually diminishes from $40 \mathrm{~mm}$ in the proximal sections until the distal ileum in an adult human. ${ }^{26}$ More flexible intestine models were made of $40 \mathrm{~mm}$ diameter polyester urethane (PU) (Figure 6(b)). The tests on the rigid and flexible tubes in the in vitro models were carried out allowing the endoscope to advance by cycling the pneumatic cavities. After placing the system in the in vitro intestine model, the control unit regulated the movements of the pneumatic engine to allow it to advance autonomously. According to the experience of the medical team, Sulky ${ }^{\circledR}$ hydrosoluble lubricant was used to simulate the mucus. The experiment was recorded with a camera and the video was later analyzed to measure the stroke distance several times, as well as the total distance traveled and the time required to do so.

Ex vivo $38 \mathrm{~mm}$ diameter and $90 \mathrm{~cm}$ length intestine models were obtained from a $100 \mathrm{~kg}$ 6-month-old pig. Flexible and ex vivo models were placed on a support that allowed the intestine to be held in place with a system that simulated the mesentery tension (Figure 7). The tests on the ex vivo and in vivo models were controlled by a clinical endoscopy specialist, as in a real situation, so that only the Endoworm's retraction capacity was tested. In the ex vivo test, the procedure was as follows: first, the system was first introduced through an artificial anus as far as the first curve; second, the pneumatic engine was started; and third, the distance traveled each cycle was measured and the mobile balloon's grip on the intestine was evaluated.

In vivo tests were conducted on a 'Large White' $40 \mathrm{~kg}$ female pig. The intestine diameter was $32 \mathrm{~mm}$ (Figure 8). In this test, the procedure was the following: first, after pharmacological sedation, the animal was intubated and maintained by inhaled sevoflurane; second, a medium laparotomy was performed (in order to check the behavior of the system); third, a small buttonhole was made on the proximal small intestine (jejunum) loop to avoid

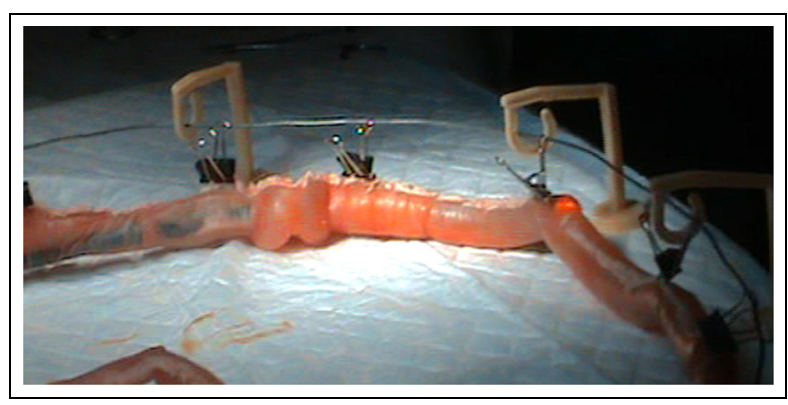

Figure 7. Endoworm system ex vivo model test.

entry through the upper reaches (mouth, esophagus, etc.) during this experimental phase; fourth, the enteroscope with the attached Endoworm system was inserted through the buttonhole; fifth, the system was initiated in the anterograde direction. The test was approved by the Ethics Committee for Animal Tests (Ref. CEEA IP.VPB. \#2-1-2016).

The system traveled at different speeds in the different models. In the rigid tube, the speed was $182 \mathrm{~mm} / \mathrm{min}$ and in the flexible model was $135 \mathrm{~mm} / \mathrm{min}$. The mean speed of advance in the ex vivo and in vivo tests was $33 \mathrm{~mm} / \mathrm{min}$.

The maximum expected stroke displacement coincides with the maximum displacement of the mobile balloon when tested in air with no interaction with an intestine model $(25 \mathrm{~mm})$. Figure 9 shows the results of stroke distance measured in the different intestine models used. As can be seen, the behavior in the rigid tube, with a mean distance traveled of $12.4 \mathrm{~mm}$ per stroke, is longer than that in the flexible PU intestine $(9.3 \mathrm{~mm}$ per stroke). In both cases, the endoscope was dragged through the Endoworm system, but in the first there was no deformation of the bowel model so that the balloon had a better grip on the wall. The PU intestine model deformed so that the pneumatic engine achieved no complete displacements. The ex vivo stroke distance $(14.9 \mathrm{~mm})$ was longer than in the other intestinal models, although in this case the medical specialist interacted in the movement. The necessary preparation of the bowel for the tests and the fact that it was not a living intestine affected the passage of the system against the wall of the bowel, and not all of the strokes contributed to the advance of the system. A statistical analysis, analysis of variance (ANOVA) test with a confidence 


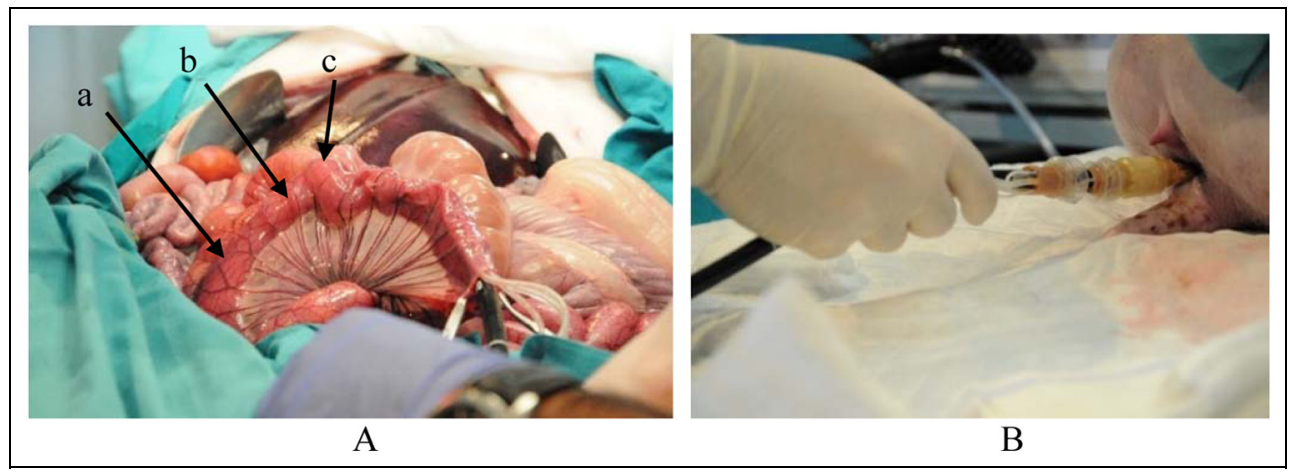

Figure 8. (A) Endoworm system introduced through the buttonhole made in the jejunum in the in vivo model: (a) distal end of endoscope, (b) inflated bellows and (c) mobile balloon inflated. (B) Endoworm anal entry.

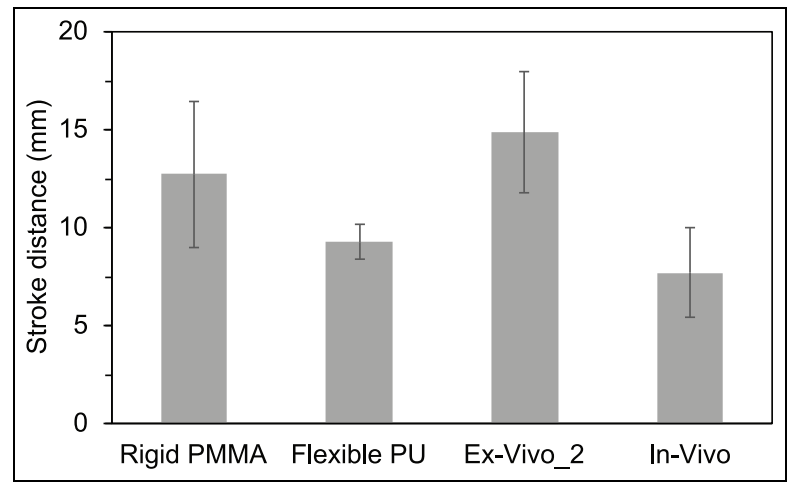

Figure 9. Stroke distance measured in different intestine models. The value represents the average of more than 15 stroke measurements and the error bars represent the standard deviation.

level of $p=0.05$, was performed ( $N=20$ replicates). The results showed that measurements inside the rigid tube present significant differences with the rest of the intestine models studied.

The worst performance was in the in vivo test, with a mean value of $7.7 \mathrm{~mm}$ per stroke. The diameter of the intestine was one of the causes, but the situation of the intestine inside the body (as can be seen in Figure 8(A)) and the presence of mucus also contributed to this poor outcome. The bellows tended to adhere to the bowel wall, hindering the movement of the system. The force exerted by the mesentery was greater than expected, and not all the strokes resulted in effective movements of the intestine. Although there were no significant differences between the stroke distance measured in the flexible PU intestine model and the corresponding value in the in vivo test, it should be taken into account that in this case the specialist helped the movement.

As the diameter of the intestine was suspected of being the problem, a second test was carried out by introducing the system by the anus (Figure $8(\mathrm{~B})$ ). Once the system was entirely inside, the movement started, and the enteroscope entered by itself with no help from the specialist, due to the balloons gripping the intestinal wall. This can be explained by two reasons: on the one hand, the diameter of the large intestine is bigger than in the small bowel. On the other hand, the colon is fixed to neighboring structures to a greater extent than in the small bowel, with better anchorage, allowing the system to propel itself and even drag the endoscope with it. The extraction of the system by the anus was also successful, after which the system remained 100\% functional.

\section{Conclusion}

This article describes the designing and testing of the third-generation Endoworm system, a semiautonomous device that consists of a series of inflatable cavities (two balloons and a bellows) governed by a control unit. The device can be adapted to any commercial endoscope. The coordinated inflation and deflation of the cavities causes the small bowel to retract and the endoscope to advance. Silastic 7-6830 silicone was selected for the bellows cavity and Silastic Q7-4720 silicone for the balloons. The complete system was attached to a commercial Olympus SIF-Q180 enteroscope and tested in vitro in a rigid methacrylate tube, a more flexible PU tube, an ex vivo model and an in vivo animal model. The system showed good behavior and was able to propel itself and the endoscope in the in vitro tests. The mean stroke distance was measured and the performance of the device was evaluated in different intestine models. The best results (longest stroke distance and best speed) were observed in the rigid tube. Although this tube could not be considered a realistic model, it enables to check the system behavior in a controlled environment. On the other hand, the stroke distance results suggest that the more flexible PU model could be considered an appropriate intestine model.

The in vivo tests revealed the system's present shortcomings; not enough force is exerted to overcome the tension of the mesentery on the intestine so that another method of generating this force is required. More tests on mature pigs (with larger intestinal diameters) would thus be desirable. However, when the system was introduced through the anus, its behavior in the large intestine was as good as in the in vitro tests. The in vivo tests showed the dependence of the system's performance on the mechanical properties of the lumen, while the 
experiments on the animal model suggest that the device should be modified in order to improve its defects (force achieved by the bellows) while maintaining its good performance in the radial expansion of the cavities.

\section{Declaration of conflicting interests}

The author(s) declared no potential conflicts of interest with respect to the research, authorship, and/or publication of this article.

\section{Funding}

The author(s) disclosed receipt of the following financial support for the research, authorship, and/or publication of this article: The authors gratefully acknowledge the financial support from the Spanish Ministry of Economy and Competitiveness through Project PI12/01000 and also from UPV/IIS LA Fe through the Endoworm 3.0 Project. CIBER-BBN is an initiative funded by the VI National R\&D\&I Plan 2008-2011, Iniciativa Ingenio 2010, Consolider Program and CIBER Actions, and financed by the Instituto de Salud Carlos III with the assistance of the European Regional Development Fund.

\section{References}

1. Yamamoto H, Sekine Y, Sato Y, et al. Total enteroscopy with a nonsurgical steerable double-balloon method. Gastrointest Endosc 2001; 53(2): 216-220.

2. Sunada K and Yamamoto H. Double-balloon endoscopy: past, present, and future. J Gastroenterol 2009; 44(1): $1-12$.

3. Tsujikawa T, Saito Y, Imaeda H, et al. Clinical impact of novel single balloon enteroscopy. $J$ Gastroenterol Hepatol 2007; 22: A226.

4. Akerman PA and Haniff M. Spiral enteroscopy: prime time or for the happy few? Best Pract Res Clin Gastroenterol 2012; 26(3): 293-301.

5. Iddan G, Meron G, Glukhovsky A, et al. Wireless capsule endoscopy. Nature 2000; 405(6785): 417.

6. Ciuti G, Calio R, Camboni D, et al. Frontiers of robotic endoscopic capsules: a review. J Microbio Robot 2016; 11: $1-18$.

7. Fukumoto A, Tanaka S, Shishido T, et al. Comparison of detectability of small-bowel lesions between capsule endoscopy and double-balloon endoscopy for patients with suspected small-bowel disease. Gastrointest Endosc 2009; 69(4): 857-865.

8. Khashab MA, Lennon AM, Dunbar KB, et al. A comparative evaluation of single-balloon enteroscopy and spiral enteroscopy for patients with mid-gut disorders. Gastrointest Endosc 2010; 72(4): 766-772.

9. May A, Faerber M, Aschmoneit I, et al. Prospective multicenter trial comparing push-and-pull enteroscopy with the single- and double-balloon techniques in patients with small-bowel disorders. Am J Gastroenterol 2010; 105(3): 575-581.

10. Yanagida T, Adachi K, Yokojima M, et al. Development of a peristaltic crawling robot attached to a large intestine endoscope using bellows - type artificial rubber muscles. In: IEEE/RSJ international conference on intelligent robots and systems, Vilamoura, 7-12 October 2012, pp.2935-2940. New York: IEEE.

11. Chen W-G, Shan G-D, Zhang H, et al. Double-balloon enteroscopy in small bowel diseases: eight years singlecenter experience in China. Medicine 2016; 95(42): e5104.

12. Mensink PBF, Haringsma J, Kucharzik T, et al. Complications of double balloon enteroscopy: a multicenter survey. Endoscopy 2007; 39(7): 613-615.

13. Shinozaki S, Yano T, Sakamoto H, et al. Long-term outcomes in patients with overt obscure gastrointestinal bleeding after negative double-balloon endoscopy. Dig Dis Sci 2015; 60(12): 3691-3696.

14. Shimatani M, Hatanaka H, Kogure H, et al. Diagnostic and therapeutic endoscopic retrograde cholangiography using a short-type double-balloon endoscope in patients with altered gastrointestinal anatomy: a multicenter prospective study in Japan. Am J Gastroenterol 2016; 111(12): 1750-1758.

15. García-Correa JJE, Ramírez-García JJ, García-Contreras LF, et al. Double-balloon enteroscopy: indications, approaches, diagnostic and therapeutic yield, and safety. Early experience at a single center. Rev Gastroenterol Mex 2018; 83(1): 31-40.

16. Lenz P and Domagk D. Double- vs. and spiral enteroscopy. Best Pract Res Clin Gastroenterol 2012; 26(3): 303-313.

17. Grundfest W, Slatkin AB, Burdick J, et al. The development of a robotic endoscope. In: IEEE/RSJ international conference on intelligent robots and systems. Human robot interaction and cooperative robots, Pittsburgh, PA, 5-9 August 1995, vol. 2, pp.162-171. New York: IEEE.

18. Menciassi A and Dario P. Bio-inspired solutions for locomotion in the gastrointestinal tract: background and perspectives. Philos Trans A Math Phys Eng Sci 2003; 361(1811): 2287-2298.

19. Glozman D, Hassidov N, Senesh M, et al. A selfpropelled inflatable earthworm-like endoscope actuated by single supply line. IEEE T Biomed Eng 2010; 57(6): 1264-1272.

20. Kim Y-T and Kim D-E. Novel propelling mechanisms based on frictional interaction for endoscope robot. Tribol Trans 2010; 53(2): 203-211.

21. Zarrouk D, Sharf I and Shoham M. Analysis of wormlike robotic locomotion on compliant surfaces. IEEE T Biomed Eng 2011; 58(2): 301-309.

22. Kassim I, Phee L, Ng WS, et al. Locomotion techniques for robotic colonoscopy. IEEE Eng Med Biol 2006; 25(3): 49-56.

23. Dehghani H, Pourghodrat A, Terry B, et al. Semi-autonomous locomotion for diagnostic endoscopy device. $J$ Med Devices 2015; 9(3): 030931.

24. Yeung BPM and Chiu PWY. Application of robotics in gastrointestinal endoscopy: a review. World $J$ Gastroenterol 2016; 22(5): 1811-1825.

25. Pons Beltrán V, Sanchez Diaz C, Santonja Gimeno A, et al. Results of the in vitro utilization of an automated device of movement (Endoworm) adapted to a conventional enteroscopy. Endoscopy 2009; 41: A45.

26. Pérez-Cuadrado Martínez E, Esteban Delgado P, Latorre Reviriego R, et al. Enteroscopy. 1st ed. Madrid: Sulime Diseño de Soluciones, 2014, pp. 285-296. 